\title{
On-chip determination of C-reactive protein using magnetic particles in continuous flow
}

\author{
Chayakom Phurimsak, ${ }^{\mathrm{a}}$ Mark D. Tarn, ${ }^{\mathrm{a}}$ Sally A. Peyman, ${ }^{\mathrm{a} \dagger}$ John Greenman ${ }^{\mathrm{b}}$ and Nicole Pamme ${ }^{\mathrm{a} *}$ \\ ${ }^{a}$ Department of Chemistry, The University of Hull, Cottingham Road, Hull, HU6 7RX, UK. \\ ${ }^{\mathrm{b}}$ School of Biological, Biomedical and Environmental Sciences, The University of Hull, Cottingham Road, Hull, HU6 7RX, \\ UK.
}

\begin{abstract}
We demonstrate the application of a multilaminar flow platform, in which functionalised magnetic particles are deflected through alternating laminar flow streams of reagents and washing solutions via an external magnet, for the rapid detection of the inflammatory biomarker, C-reactive protein (CRP). The two-step sandwich immunoassay was accomplished in less than 60 seconds, a vast improvement on the 80-300 min timeframe required for ELISA and the 50 min necessary for off-chip magnetic particle-based assays. The combination of continuous flow and a stationary magnet enables a degree of autonomy in the system, while a detection limit of $0.87 \mu \mathrm{g} \mathrm{mL}^{-1}$ makes it suitable for the determination of CRP concentrations in clinical diagnostics. Its applicability was further proven by assaying real human serum samples and comparing those results to values obtained using standard ELISA tests.
\end{abstract}

\section{INTRODUCTION}

C-reactive protein (CRP), an acute phase protein, is an inflammatory biomarker found in blood whose concentration increases when the body experiences inflammation or infection, and as such is important in clinical diagnostics. ${ }^{1,2}$ Normal levels are typically $1-10 \mu \mathrm{g} \mathrm{mL}^{-1}$ while levels higher than this can indicate inflammation, viral infection $\left(10-40 \mu \mathrm{g} \mathrm{mL}^{-1}\right)$ or bacterial infection $\left(40-200 \mu \mathrm{g} \mathrm{mL}^{-1}\right)$. There is also evidence that CRP may be an indicator of cardiovascular disease (CVD), ${ }^{3-6}$ with concentrations below $1 \mu \mathrm{g} \mathrm{mL}^{-1}$ suggesting a low risk of developing CVD, while levels of 1-3 $\mu \mathrm{g} \mathrm{mL}^{-1}$ indicate an average risk and those above $3 \mu \mathrm{g} \mathrm{mL}^{-1}$ suggest a high risk. $^{7}$ For these tests, high sensitivity CRP (hs-CRP) techniques are usually performed, employing enzyme-linked immunosorbent assays (ELISA) or nephelometry. While ELISA has very low detection limits for CRP $\left(1 \mathrm{ng} \mathrm{mL}^{-1}\right),{ }^{8}$ the limits for nephelometry are relatively high ( commonly $>5 \mu \mathrm{g}$ $\left.\mathrm{mL}^{-1}\right),{ }^{9}$ and both methods can be time-consuming, with ELISA tests in particular requiring $\sim 80 \mathrm{~min}$.

The use of magnetic particles as solid supports has recently become increasingly popular for clinical diagnostics due to their small sizes $(0.2-100 \mu \mathrm{m})$, high surface-to-volume ratios, variety of biomolecules surface functionalities (e.g. antibodies, DNA), and the ease with which they can be manipulated via an applied magnetic field. ${ }^{10,11}$ With these beneficial properties, they have found use in a number of immunoassay procedures, ${ }^{11}$ including the detection of CRP. ${ }^{12-15}$ However, conventional magnetic particle-based assays that take place in a well or vial require many manual reaction and washing steps (Figure 1a,b) that make this batch process laborious and timeconsuming ( $\sim 50 \mathrm{~min})$.
In recent years, microfluidic devices ${ }^{16}$ have been developed for performing immunoassays ${ }^{17,18}$ within networks of channels that have dimensions on the order of 10-100 $\mu \mathrm{m}$. Such devices allow very small volumes to be processed, reducing sample and reagent volumes as well as waste production, while diffusion distances are shortened to allow fast and controlled reactions. Several microfluidic systems have been developed for CRP immunoassays, ${ }^{8,9,19-28}$ and while some feature impressive

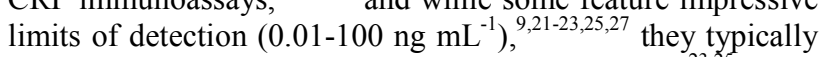
require $>20$ min with only a handful of exceptions. ${ }^{23,25}$ Often these devices require complex fabrication procedures to produce integrated components, arrays, or stencils. The majority also require fluorescence imaging of a large area, which may contain arrays of detection zones, in order to perform an analysis, thus requiring fluorescence microscopy which limits the path to overall miniaturisation and portability.

The combination of magnetic particles in microfluidic platforms has exploited the benefits of both fields for a number of processes, ${ }^{29-31}$ including immunoassays. ${ }^{32}$ However, many techniques involve the trapping of particles and subsequent exposure to reagents, ${ }^{9,37-40}$ hence suffering from the same laborious and time-consuming steps as conventional magnetic particle assays. A recent solution to this problem has been the introduction of "multilaminar flow" procedures for performing assays and other processes. ${ }^{33}$ Here, alternating streams of reagents and washing buffer solutions are generated across a chamber. Functionalised particles are then deflected laterally through the each of the streams, allowing consecutive reaction and washing steps to take place. This technique effectively reduces multi-stage processes into a single, automated step that reduces assay times considerably and eliminates the multiple manual operations associated with batch assays. Magnetic particles provide an excellent solid phase for this process as 
their deflection can be achieved via a small, inexpensive, stationary permanent magnet. Previously, we have demonstrated their use for streptavidin-biotin binding assays, ${ }^{34,35}$ immunoglobulin G (IgG) assays, ${ }^{35,36}$ DNA hybridisation, ${ }^{36,37}$ and polymer deposition. ${ }^{38}$ Other groups have also developed similar systems utilizing "zig-zag"-based magnetic particle deflection for assays, ${ }^{39-42}$ the capture of oligonucleotides ${ }^{43}$ and cells, ${ }^{44}$ DNA extraction ${ }^{45,46}$ and particle coating. ${ }^{47,48}$

Here, we demonstrate the first application of our multilaminar flow platform for the rapid detection of CRP via a sandwich immunoassay (Figure 1c). Primary antibody functionalised magnetic particles are introduced into a chamber in the $\mathrm{x}$-direction and deflected in the y-direction via a magnet, crossing consecutive streams of CRP (standard or sample), washing buffer, fluorescently labelled secondary antibody, and into a final washing buffer. We first investigate the optimisation of various parameters, before performing assays on real human serum samples. Furthermore, we compare those results to data obtained by traditional ELISA techniques for validation of our system.

\section{EXPERIMENTAL}

\section{Chip fabrication and setup}

The microfluidic chip design consisted of five inlet channels and five outlet channels connected to an $8 \times 3 \mathrm{~mm}^{2}$ deflection chamber, which was supported by ten square posts (Figure 2a). The devices were fabricated in glass (Telic, USA) to a depth of $20 \mu \mathrm{m}$ using standard photolithography and wet etching procedures. ${ }^{49}$ Access holes were drilled into the glass plate, which was thermally bonded to a glass top plate (Figure

(a)

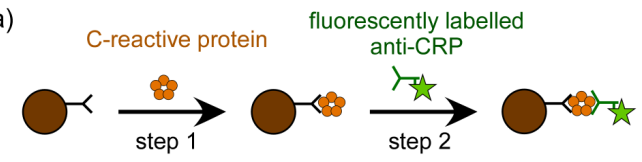

magnetic particles with anti-CRP

(b)
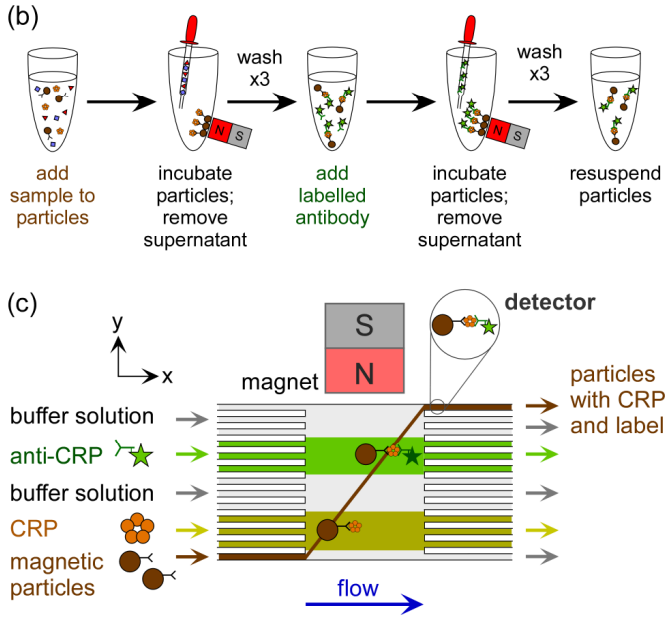

Figure 1. (a) Principle of the two-step C-reactive protein sandwich immunoassay. (b) Schematic of a conventional off-chip magnetic particlebased assay, including multiple washing steps. (c) Operation of the multilaminar flow platform for a CRP sandwich assay, in which functionalized magnetic particles are pulled through alternating streams of reagents and washing buffers via an external magnet.
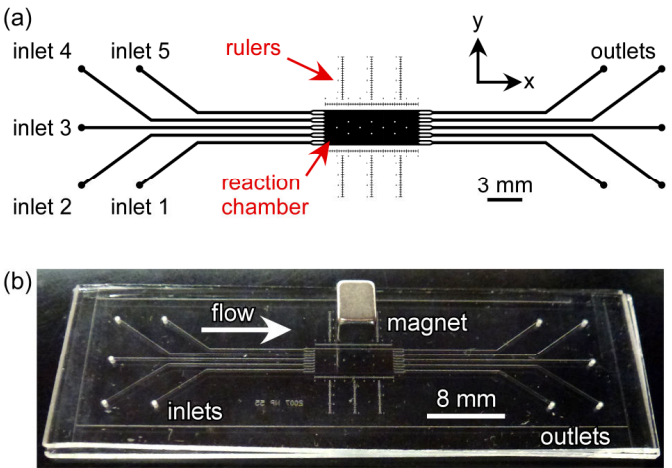

(c)

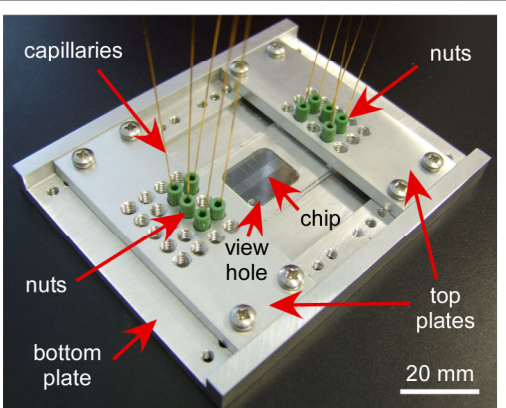

Figure 2. (a) Schematic of the microfluidic device, showing the five inlets and five outlets, the reaction chamber, and the ruler structures used for positioning of the magnet. (b) Photograph of the device fabricated in glass, with a $4 \times 4 \times 5 \mathrm{~mm}^{3} \mathrm{NdFeB}$ magnet positioned on top of the chip. (c) Photograph of the microfluidic device situated in a custom-built chip holder, with capillaries interfaced via nuts and ferrules to the access holes of the chip.

2b). The chip was inserted into an aluminium chip holder that was fabricated in-house (Figure 2c), and which allowed interfacing of the access holes to fused silica capillaries $(150 \mu \mathrm{m}$ i.d., $363 \mu \mathrm{m}$ o.d., CM Scientific, UK). The inlet capillaries were attached at the other end to syringes, which were placed on a syringe pump (PHD 22/2000, Harvard Apparatus, UK). The outlet capillaries had Tygon tubing ( $0.254 \mathrm{~mm}$ i.d., ColeParmer, UK) connected to them, and this was fed into a waste collection vial. Solutions were pumped through the microfluidic chip at a flow rate of $20-100 \mu \mathrm{L} \mathrm{h}^{-1}$ per syringe, giving a total flow rate of $100-500 \mu \mathrm{L} \mathrm{h}^{-1}\left(458-2291 \mu \mathrm{m} \mathrm{s}^{-1}\right)$ in the chamber.

An inverted fluorescence microscope (TE-2000, Nikon, UK) with a CCD camera (Retiga-EXL, Media Cybernetics, UK) was used to capture images and videos, which were analysed using ImageJ software (http://rsb.info.nih.gov/ij/). Experiments were typically performed at room temperature $(20$ ${ }^{\circ} \mathrm{C}$ ), but during some tests the temperature was varied using a temperature controlled sample stage (PE100-NIF, Linkam Scientific Instruments Ltd., UK). In this case, the chip holder was not used, and instead the capillaries were glued directly into the access holes of the chip using Araldite Epoxy glue (RS Components, UK) so that the chip could be in contact with the heated stage.

A 4 × 4 × $5 \mathrm{~mm}^{3}$ rectangular neodymium-iron-boron $(\mathrm{NdFeB})$ magnet (Magnet Sales, UK) was placed on top of the microfluidic chip, next to the deflection chamber. A set of rulers designed into the chip were used for positioning of the magnet. The magnetic flux density (B) at the surface of the 


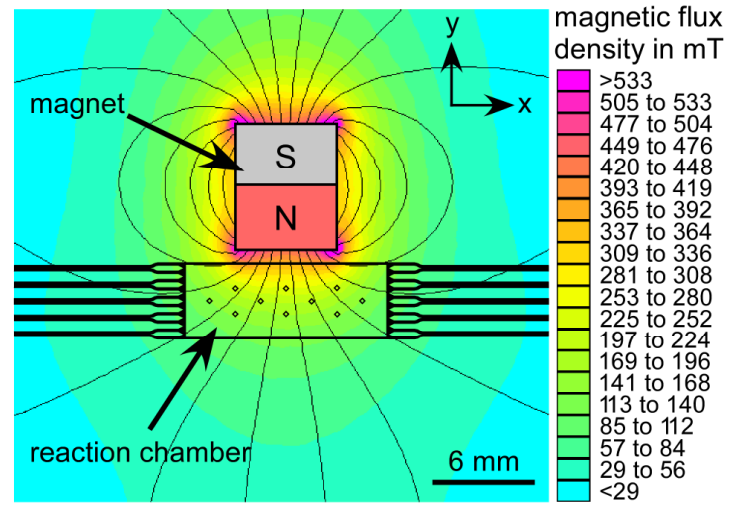

Figure 3. Simulation of the magnetic flux density across the microfluidic chamber, modelled using FEMM software.

magnet was calculated to be $561 \mathrm{mT}$. A simulation of $\mathbf{B}$ across the deflection chamber of the chip (Figure 3) was prepared using FEMM 4.2 software (http://femm.foster-miller.net), and this was used to estimate a representative value of $\mathbf{B}$ at the centre of the chamber of $136 \mathrm{mT}$, with a gradient $(\nabla \mathbf{B})$ across the chamber of $44 \mathrm{mT} \mathrm{mm}^{-1}$, and an estimated $(\mathbf{B} \cdot \nabla) \mathbf{B}$ value of $6 \mathrm{~T}^{2} \mathrm{~m}^{-1}$.

\section{Preparation of solutions and particle suspensions}

All solutions were prepared in high purity water (18.2 $\mathrm{M} \Omega$ $\mathrm{cm}$ at $25^{\circ} \mathrm{C}, 0.05 \mu \mathrm{m}$ filtered) unless otherwise stated. Phosphate buffered saline solution (PBS, $\mathrm{pH}$ 7.45) was prepared with $0.01 \% \mathrm{w} / \mathrm{v}$ bovine serum albumin (BSA) added to reduce non-specific binding of reagents and particles sticking. C-reactive protein (CRP, R\&D Systems, UK) solutions were prepared in PBS buffer to concentrations of $1-10 \mu \mathrm{g} \mathrm{mL}^{-1}$. Biotinylated primary CRP antibody ( $1^{\circ} \mathrm{Ab}, \mathrm{R} \& \mathrm{D}$ Systems) was prepared in PBS buffer to concentrations of $1-15 \mu \mathrm{g} \mathrm{mL}^{-1}$. Fluorescently labelled secondary CRP antibody $\left(2^{\circ} \mathrm{Ab}\right.$-FITC, Abcam, UK) was prepared in PBS buffer to concentrations of 10-200 $\mu \mathrm{g} \mathrm{mL} \mathrm{m}^{-1}$.

Human serum samples were collected from three volunteers and stored at $-20{ }^{\circ} \mathrm{C}$ until ready for use. The samples were fully anonymized and no clinical details were recorded, and had been obtained as part of an ethically approved earlier study in circulating biomarkers in colorectal cancer patients.

Streptavidin functionalised magnetic particles (Dynabeads M-270 Streptavidin, $2.8 \mu \mathrm{m}$ diameter) were purchased from Invitrogen. $10 \mu \mathrm{L}$ of stock particle suspension in a polypropylene tube (VWR, UK) was mixed with $200 \mu \mathrm{L}$ of $1^{\circ} \mathrm{Ab}$ solution at a concentration between $1-15 \mu \mathrm{g} \mathrm{mL} L^{-1}$, then incubated for $15 \mathrm{~min}$ to bind the biotinylated antibodies particle surface. The "activated" particles were then washed three times with PBS buffer, then resuspended in PBS buffer solution $(1000 \mu \mathrm{L})$ to yield a final particle concentration of $6.7 \mathrm{x}$ $10^{6}$ particles $\mathrm{mL}^{-1}$.

\section{Off-chip C-reactive protein assays}

The CRP sandwich immunoassay was optimised off-chip prior to performing the assay in the microfluidic device. 200 $\mu \mathrm{L}$ of the activated $\left(1^{\circ} \mathrm{Ab}\right)$ magnetic particle suspension was added to a polypropylene tube, the particles collected at the side of the tube via a magnet, and the supernatant was removed. $200 \mu \mathrm{L}$ of CRP $\left(1-10 \mu \mathrm{g} \mathrm{mL}^{-1}\right)$ was added and incu- bated for 15 min with agitation. Following this, the particles were again pulled to the side of the tube via a magnet, and the particles washed three times with PBS. $200 \mu \mathrm{L}$ solution of $2^{\circ}$ Ab-FITC (10-200 $\left.\mu \mathrm{g} \mathrm{mL}^{-1}\right)$ was added and allowed to incubate for $15 \mathrm{~min}$ with agitation, then the particles washed three times with PBS, finally being resuspended in $1000 \mu \mathrm{L}$ PBS. Samples were taken at various stages of the process and pipetted onto a microscope slide for fluorescence analysis.

\section{On-chip C-reactive protein assay}

Prior to on-chip experiments, the microfluidic chip was washed consecutively with ethanol, water, and PBS buffer. Following this, activated $\left(1^{\circ} \mathrm{Ab}\right)$ magnetic particles $\left(6.7 \times 10^{6}\right.$ particles $\mathrm{mL}^{-1}$ ) was pumped into inlet 1 , CRP solution into inlet 2 , secondary antibody solution $\left(2^{\circ} \mathrm{Ab}\right.$-FITC) into inlet 4 , and PBS buffer solution into inlets 3 and 5, via the syringe pump. The effects of $2^{\circ}$ Ab-FITC (1-100 $\left.\mu \mathrm{g} \mathrm{mL}^{-1}\right)$ and CRP (1-10 $\mu \mathrm{g} \mathrm{mL}^{-1}$ ) concentration were studied, while the effect of temperature was also examined at $20{ }^{\circ} \mathrm{C}$ and $40{ }^{\circ} \mathrm{C}$. Human serum samples were tested by introducing the serum into inlet 2 of the device, replacing the CRP standard solutions.

\section{ELISA analysis of human serum samples}

In order to compare on-chip results of the human serum samples, they were also tested using a hs-CRP ELISA test kit from MP Biomedicals (Fisher Scientific, UK) as per the manufacturer's instructions. The presence of CRP yielded a yellow colour, the intensity of which was directly proportional to the concentration of CRP.

\section{RESULTS}

\section{Off-chip C-reactive protein assays}

Off-chip assays were performed in order to ensure that the proposed magnetic particle-based method was suitable for the detection of CRP. Particular attention was paid to the parameters of the particle activation step, in which the magnetic particles were functionalised with biotinylated primary CRP antibody $\left(1^{\circ} \mathrm{Ab}\right)$, and which would take place off-chip prior to the introduction of the particles into the microfluidic device.

Firstly, the concentration of $1^{\circ} \mathrm{Ab}$ during the preparation of the magnetic particles was varied from 1 to $15 \mu \mathrm{g} \mathrm{mL}^{-1}$ and incubated for $15 \mathrm{~min}$, before completion of the sandwich assay $\left([\mathrm{CRP}]=10 \mu \mathrm{g} \mathrm{mL}^{-1},\left[2^{\circ} \mathrm{Ab}-\mathrm{FITC}\right]=100 \mu \mathrm{g} \mathrm{mL}^{-1}\right)$. The resulting fluorescence intensities of the magnetic particles were measured and demonstrated that the fluorescence signal started to plateau at $\sim 10 \mu \mathrm{g} \mathrm{mL}^{-1}$ of $1^{\circ} \mathrm{Ab}$ (Figure $\mathrm{S}-2 \mathrm{a}$ in the $\mathrm{SI}$ ). Therefore, $10 \mu \mathrm{g} \mathrm{mL}^{-1}$ was employed for the activation step for all subsequent experiments. The incubation time of the $1^{\circ}$ $\mathrm{Ab}$ activation step was also varied from 1 to $30 \mathrm{~min}$ to determine its effect $\left(\left[1^{\circ} \mathrm{Ab}\right]=10 \mu \mathrm{g} \mathrm{mL}^{-1},[\mathrm{CRP}]=10 \mu \mathrm{g} \mathrm{mL}^{-1}\right.$, $\left[2^{\circ} \mathrm{Ab}\right.$-FITC $\left.]=100 \mu \mathrm{g} \mathrm{mL}^{-1}\right)$. The resulting fluorescence intensities of the particles actually showed little difference (Figure S-2b in the SI), indicating fast kinetics that would be expected of the streptavidin-biotin interaction. However, to ensure saturation of the antibody, the incubation time was kept at 15 min for all subsequent experiments.

Optimisation of the CCD camera exposure time was undertaken by measuring the fluorescence intensity of reacted particles with exposure times ranging from 0.1 to $2 \mathrm{~s}$. By comparing the ratios of the particle intensities against the background 
intensities, it was found that an exposure time of $0.7 \mathrm{~s}$ yielded the best results in terms of signal-to-noise ratio (Figure S-3a,b in the SI). Exposure times $>1 \mathrm{~s}$ yielded lower intensities, presumably due to photobleaching (Figure S-3c in the SI), giving further evidence for employing an exposure time of $0.7 \mathrm{~s}$, which was used for the remainder of the experiments.

Negative control tests were also performed in which one of the reagents $\left(1^{\circ} \mathrm{Ab}, \mathrm{CRP}, 2^{\circ} \mathrm{Ab}\right.$-FITC) in each test was replaced with PBS buffer. The results showed no increase in fluorescence intensity, indicating that the reaction did not occur without the presence of all of the reagents.

These off-chip tests confirmed the applicability of the magnetic particle-based CRP assay, and allowed the optimisation of the particle activation step. Furthermore, they highlighted the laborious nature of the off-chip assays, such as the multiple manual steps required, the relatively large volumes of reagents employed $(200 \mu \mathrm{L})$, and the long assay times ( $\sim 50 \mathrm{~min})$.

\section{Effect of flow rate on diffusion and particle trajectories}

The laminar flow regime inside the chamber was studied by introducing alternating streams of red and yellow inks into the device at applied flow rates (i.e. the flow rate from each individual syringe) from $1-100 \mu \mathrm{L} \mathrm{h}^{-1}$, corresponding to flow rates in the chamber of 5-500 $\mu \mathrm{L} \mathrm{h}^{-1}\left(22.9-2291 \mu \mathrm{m} \mathrm{s}^{-1}\right)$. Stable flow was observed across all of the flow rates (Figure S-4a in the $\mathrm{SI}$ ), and no diffusion was observed between streams 2 (representing CRP) and 4 (representing $2^{\circ} \mathrm{Ab}$-FITC) at flow rates in the chamber down to $50 \mu \mathrm{L} \mathrm{h}^{-1}$ in the chamber. However, at the lowest applied flow rate tested of $5 \mu \mathrm{L} \mathrm{h}^{-1}$ (in the chamber), the diffusion of the streams became problematic, with the contents of streams 2 and 4 actually crossing stream 3 and starting to mix with each other (Figure S-4b in the SI). This was confirmed by plotting the greyscale values across the width of the chamber near to the outlet using ImageJ software (Figure S-4c in the SI). Thus, provided the chamberflow rates were $50 \mu \mathrm{L} \mathrm{h}^{-1}$ or higher, diffusion between reagent streams would not be problematic.

The magnetic particle trajectories were also examined at different flow rates in the presence of the stationary NdFeB magnet next to the chamber. Particle suspension was pumped into inlet 1 of the device with PBS buffer introduced into the remaining outlets (2-5), and the flow rate of the solutions in the

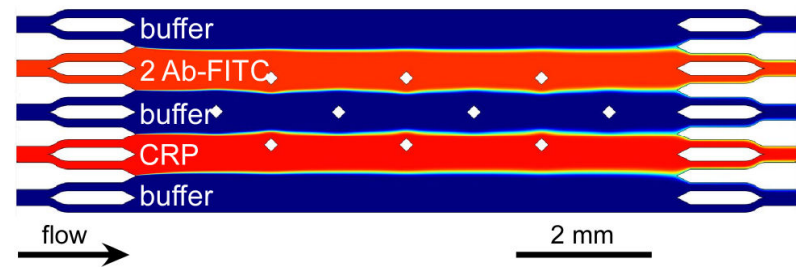

Figure 4. Superimposed simulations showing the diffusion of CRP and $2^{\circ} \mathrm{Ab}-\mathrm{FITC}$ they pass through the microfluidic chamber. The original, individual simulations can be found in the ESI (Fig. S6), together with their respective legends.

chamber was varied from 100 to $500 \mu \mathrm{L} \mathrm{h}^{-1}$ (458 to $2291 \mu \mathrm{m}$ $\mathrm{s}^{-1}$ ) (Figure S-5 in the SI). The results showed that the particles at a flow rate of $500 \mu \mathrm{L} \mathrm{h}^{-1}$ and $250 \mu \mathrm{L} \mathrm{h}^{-1}$ were unable to cross the entire width of the chamber, while at $100 \mu \mathrm{L} \mathrm{h}^{-1}$ they migrated across the entire width but then aggregated against the top wall (in the y-direction) of the chamber. The optimum flow rate was thus between these, and was determined to be $200 \mu \mathrm{L} \mathrm{h}^{-1}\left(916 \mu \mathrm{m} \mathrm{s}^{-1}\right)$.

\section{Flow and diffusion simulations}

Having established that $200 \mu \mathrm{L} \mathrm{h}^{-1}$ was the optimum flow rate in the chamber (i.e. $40 \mu \mathrm{L} \mathrm{h}^{-1}$ on the syringe pump) for magnetic particle deflection, the diffusion of the reagent species across the chamber at this flow rate was simulated. The simulations were prepared in COMSOL Multiphysics 4.0a, and showed the diffusion of CRP and $2^{\circ} \mathrm{Ab}$-FITC from streams 2 and 4, respectively (Figure 4). Further details of the model parameters are given in the SI. It should be noted that Figure 4 was constructed from superimposed simulations for the two reagent streams, while the originals can be found in the SI (Figures S-6a,b). The concentration profiles of the $2^{\circ}$ Ab-FITC and CRP streams across the width of the chamber, $600 \mu \mathrm{m}$ from the outlets, were plotted from the individual simulations (Figure S-6c in the SI). These plots confirmed that the diffusion of the two species was not sufficient to allow mixing across the central buffer stream. Simulations of the velocity magnitude (Figure S-7a) and the pressure (Figure S7b) across the microfluidic chamber were also plotted, and these can be seen in the SI.

On-chip C-reactive protein assay

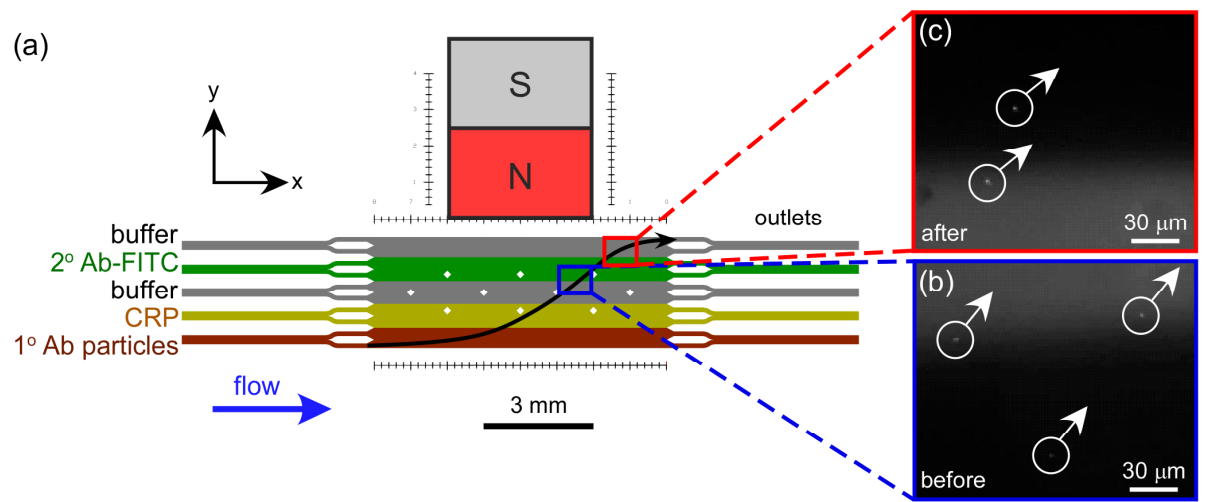

Figure 5. (a) Chip schematic demonstrating the reagents and washing buffers being pumped into the device, and the locations at which photographs of particles were taken (b) before and while entering the $2^{\circ} \mathrm{Ab}$-FITC stream, and (c) after the particles had been deflected through the laminar flow streams. 

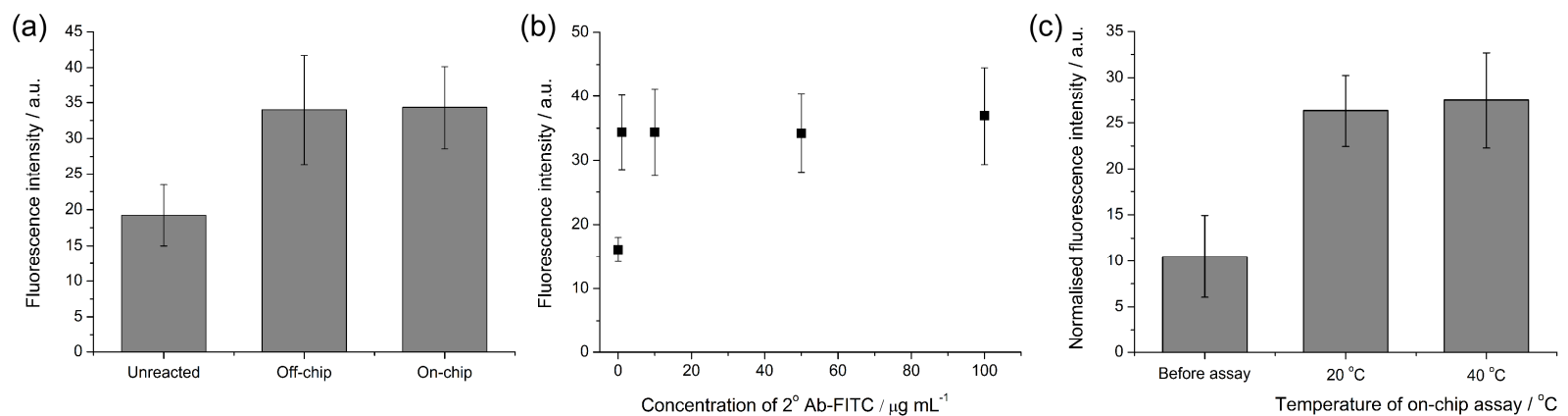

Figure 6. (a) Comparison of magnetic particle fluorescence intensities between those reacted off-chip, and those reacted on-chip then collected for off-chip analysis. (b) Effect of secondary antibody concentration $\left(2^{\circ}\right.$ Ab-FITC) on fluorescence intensity in multilaminar flow assays. (c) Effect of temperature on the multilaminar flow sandwich assays.

Having established the optimum flow rate, the solutions in the chamber were replaced with $1^{\circ} \mathrm{Ab}$ activated magnetic particles in inlet $1, \mathrm{CRP}$ in inlet $2,2^{\circ} \mathrm{Ab}$-FITC in inlet 4 , and PBS buffer in inlets 3 and 5. The magnetic particles were deflected across the width of the chamber towards the stationary magnet as they followed the direction of flow, crossing each of the reagent and washing laminar flow streams in turn (Figure 5a). This allowed consecutive binding of CRP, washing, labeling, and a final washing step. Fluorescence images of the particles were taken before (Figure 5b) and after (Figure 5c) passing through the $2^{\circ} \mathrm{Ab}$-FITC stream, and demonstrate the increase in fluorescence intensity that indicated successful CRP binding and labelling.

A series of negative tests were performed in which one of the reagents $\left(1^{\circ} \mathrm{Ab}, \mathrm{CRP}, 2^{\circ} \mathrm{Ab}\right.$-FITC) was removed from the procedure each time and replaced with PBS buffer solution instead. In each case the particles did not exhibit higher fluorescence intensities than their auto-fluorescence values, showing that the assay would not work without having all of the components present. This also demonstrated that the final PBS washing stream was sufficient to wash any unbound $2^{\circ} \mathrm{Ab}$ FITC as no fluorescence increase was observed when CRP was not present.

Importantly, the assay procedure, i.e. the crossing of the particles across the width of the reaction chamber, took only around 60 seconds, a vast reduction in processing time that would normally be required using conventional techniques such as off-chip magnetic particle assays and ELISA. In addition, manual operations were virtually eliminated since once the solutions and particles were being pumped through the chip the procedure was essentially autonomous.

In a separate test, the particles were collected from the chip and their fluorescence intensities were compared to particles that had been reacted using the conventional off-chip technique (Figure 6a). The fluorescence intensities were found to be very similar, indicating that the efficiency of the on-chip reaction was similar to the conventional method, even with the much shorter incubation times (60 s) in the former case.

\section{Effect of secondary antibody concentration}

The effect of $2^{\circ} \mathrm{Ab}$-FITC concentration in the on-chip assay was investigated by repeating the experiment with varying concentrations $\left(1-100 \mu \mathrm{g} \mathrm{mL}{ }^{-1}\right)$ of $2^{\circ}$ Ab-FITC, while the CRP concentration was maintained at $1 \mu \mathrm{g} \mathrm{mL}^{-1}$. The results are shown in Figure 6b, and demonstrated little change in the fluorescence signal of the particles between across the concentration range. The signal showed a very slight increase at 100 $\mu \mathrm{g} \mathrm{mL} \mathrm{m}^{-1}$ of $2^{\circ} \mathrm{Ab}$-FITC, which may have ensured saturation of the CRP binding sites more effectively than lower concentrations. Although the concentration of $2^{\circ}$ Ab-FITC was apparently not a vital factor for the assay in the range tested, it was decided that $100 \mu \mathrm{g} \mathrm{mL}^{-1}$ would be used in further experiments to ensure saturation of any particle-bound CRP.

\section{Effect of temperature on the on-chip assay}

Immunoassays are often performed at $37^{\circ} \mathrm{C}$, however the optimisation of the magnetic particle-based assays had taken place at room temperature $\left(20{ }^{\circ} \mathrm{C}\right)$. In order to determine whether increasing the temperature had an effect on the onchip CRP immunoassay $\left([\mathrm{CRP}]=1 \mu \mathrm{g} \mathrm{mL}^{-1},\left[2^{\circ} \mathrm{Ab}-\mathrm{FITC}\right]=\right.$ $100 \mu \mathrm{g} \mathrm{mL}^{-1}$ ), the experiment was repeated at temperatures of $20{ }^{\circ} \mathrm{C}$ and $40{ }^{\circ} \mathrm{C}$ using a temperature controlled sample stage. The temperature stage was calibrated by varying the programmed temperature while measuring the temperature of the stage and chip using a thermocouple (Figure S- 8 in the SI). The resulting fluorescence intensities were normalised with respect to the unreacted particles, and are shown in Figure 6c. The results showed that increasing the temperature had very little effect, with only a very minor increase in intensity observed at $40{ }^{\circ} \mathrm{C}$. Therefore, the remainder of the on-chip experiments were performed at room temperature $\left(20^{\circ} \mathrm{C}\right)$.

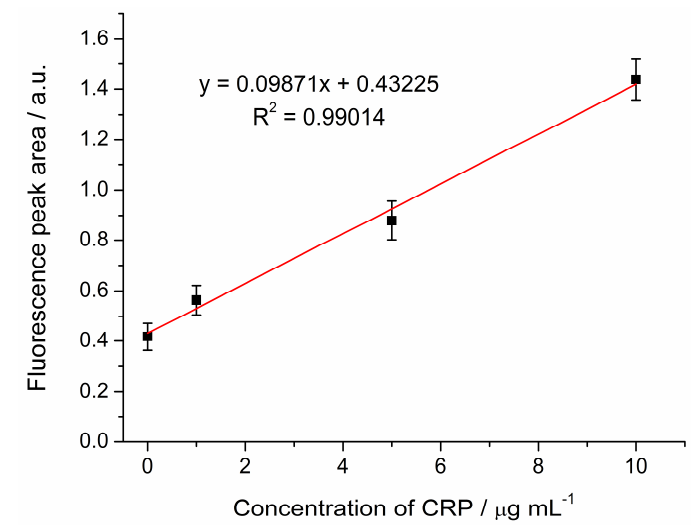

Figure 7. Calibration curve of fluorescence peak area versus CRP concentration generated via the on-chip multilaminar flow assay ( $n=5$ particles). 


\section{C-reactive protein calibration}

In order to determine the validity of the platform for quantitative assays, and for the determination of CRP concentrations in real human serum samples, experiments were repeated with CRP concentrations of 1,5 and $10 \mu \mathrm{g} \mathrm{mL}^{-1}$. The concentration of $2^{\circ} \mathrm{Ab}$-FITC was $100 \mu \mathrm{g} \mathrm{mL} \mathrm{m}^{-1}$. The plotted results are shown in Figure 7, and the graph clearly demonstrates a linear increase of fluorescence signal with increasing CRP concentration. The "fluorescence peak area" rather than fluorescence intensity was measured since the captured images showed "streaks" of particles, and the peak area better accounted for differences in particle velocities, since faster particle yield longer streaks.

Based on the standard deviation of the intercept ( $\alpha=0.02591)$, and the gradient $(S=0.09871)$, the limit of detection (LOD) of the platform was determined to be $0.87 \mu \mathrm{g}$ $\mathrm{mL}^{-1}$, given that $\mathrm{LOD}=(3.3 \alpha) / S .^{50}$ This shows that the lowest CRP concentration tested here $\left(1 \mu \mathrm{g} \mathrm{mL}^{-1}\right)$ was near to the LOD, but was well within the limits for conventional CRP testing. Furthermore, the technique should also be capable of performing hs-CRP tests, since the LOD is below the threshold value for low risk of CVD $\left(<1 \mu \mathrm{g} \mathrm{mL}{ }^{-1}\right)$. Having established a calibration curve, the determination of CRP in real human serum samples was investigated.

\section{Human serum samples}

Serum samples were collected from three volunteers and pumped into inlet 2 of the microfluidic chip during the on-chip assay. Despite the viscosity of the serum being higher than water, the magnetic particles could be easily deflected through the serum stream. After then passing through the washing and $2^{\circ}$ Ab-FITC $\left(100 \mu \mathrm{g} \mathrm{mL}{ }^{-1}\right)$ streams, the fluorescence peak areas of the moving particles were measured and their corresponding CRP concentrations determined from the graph in Figure 7. These CRP values are shown in Table 1 alongside the CRP concentrations determined via conventional ELISA analysis of the same samples. The calibration curve and real sample values obtained from the ELISA analysis are shown in Figure S-9 and Table S-1, respectively, in the SI. As before, the assay took less than $60 \mathrm{~s}$, the time required for particles to cross the width of the chamber.

Table 1. Fluorescence peak areas of magnetic particles following multilaminar flow assays, their corresponding CRP concentrations ( $\mathrm{n}=$ 5 particles), and CRP concentrations determined by ELISA $(n=2)$.

\begin{tabular}{|c|c|c|c|}
\hline \multirow{2}{*}{$\begin{array}{c}\text { Sample } \\
\text { no. }\end{array}$} & \multirow{2}{*}{$\begin{array}{c}\text { On-chip } \\
\text { fluorescence } \\
\text { peak area (a.u.) }\end{array}$} & \multicolumn{2}{|c|}{$\begin{array}{c}\text { Concentration of CRP } \\
\left(\boldsymbol{\mu} \mathbf{~ m L}^{-1}\right)\end{array}$} \\
\cline { 3 - 4 } & On-chip & ELISA \\
\hline $\mathbf{1}$ & $0.577 \pm 0.043$ & $1.47 \pm 0.11$ & $1.52 \pm 0.13$ \\
\hline $\mathbf{2}$ & $0.678 \pm 0.132$ & $2.49 \pm 0.48$ & $2.63 \pm 0.12$ \\
\hline $\mathbf{3}$ & $1.044 \pm 0.167$ & $6.20 \pm 0.99$ & $5.29 \pm 0.02$ \\
\hline
\end{tabular}

The CRP concentrations determined for samples 1 and 2 matched closely between the on-chip and ELISA techniques, but that of sample 3 was not quite so close. Therefore, a twotailed t-test was performed to compare the results of the two testing methods for each sample. In all three cases, it was de- termined that the $\mathrm{t}$-values were less than their corresponding critical values at $\mathrm{P}=0.05$, indicating no significant difference between the CRP values obtained by multilaminar flow technique and those from the standard ELISA method. These results demonstrate the applicability of the multilaminar flow platform to the measurement of real human serum samples. This bodes well for future development of the system for assaying a number of biomarkers, while improvements to the setup should allow increases in performance in terms of the limits of detection, precision of the measurements, versatility, and user-friendliness.

\section{DISCUSSION AND OUTLOOK}

The magnetic multilaminar flow platform has been demonstrated for the detection of clinically relevant biomarker from real human serum samples. The great benefit of the platform is the speed with which the assay takes place, less than $60 \mathrm{~s}$, due to the elimination of the multiple manual manipulation steps and long diffusion-based reaction times required in off-chip magnetic particle assays and in ELISA tests. The multilaminar flow technique combines reaction and washing steps into a single, automated process, with the assay time determined by how long it takes for the particles to cross the width of the chamber. This rapid assay time is enabled by directly transporting fresh reagents to the particle surfaces as they move through the reagent streams, rather than relying on diffusion of reagents within a relatively large volume well or vial.

Furthermore, while small sample volumes can be used in ELISA $(5 \mu \mathrm{L})$, reagent and washing volumes can still be relatively large $(\geq 300 \mu \mathrm{L})$, and in off-chip magnetic particles each step requires large volumes $(\geq 200 \mu \mathrm{L})$. In contrast, running the multilaminar flow system for around $5 \mathrm{~min}$ to ensure enough particles have passed through the chip for analysis will only use sample and reagent volumes of $0.7 \mu \mathrm{L}$ at $40 \mu \mathrm{L} \mathrm{h}^{-1}$. Several more $\mu \mathrm{L}$ per syringe will also be required due to dead volumes $(\sim 3.7 \mu \mathrm{L})$ and while waiting for the system to stabilize, but a typical volume should still be $<10 \mu \mathrm{L}$ and this remains a large decrease compared to the conventional methods. A summary of typical timeframes and solution volumes for each of the CRP measurement methods (ELISA, off-chip magnetic particle assays, and on-chip multilaminar flow assays) is given in Table 2, and demonstrates the benefits of the multilaminar flow technique compared to the others. Not only this, but the platform allows faster analyses than other microfluidic methods, and while other such techniques have lower detection limits this is not actually necessary for CRP assays. While we have only investigated lower concentration ranges here, corresponding to CVD monitoring, the technique can distinguish whether levels fall below or above $10 \mu \mathrm{g} \mathrm{mL}^{-1}$, thereby indicating whether inflammation or infection is present. It should also be feasible to determine whether the source of infection is bacterial $\left(>40 \mu \mathrm{g} \mathrm{mL}^{-1}\right)$ but it was not our intention to study this. One issue that may arise from investigating such high concentrations could be saturation of the signal. However, given that we are operating in the region of $\sim 35$ a.u. fluorescence intensities for our $10 \mu \mathrm{g} \mathrm{mL}^{-1}$ standards, and that the maximum is 255 a.u., it is expected that even at $40 \mu \mathrm{g} \mathrm{mL}^{-1}$ saturation would not occur. A different issue could be the saturation of antibodies of the particle surface, and this would 
require re-optimisation of some parameters or dilution of the sample.

While the multiflow system has many advantages, there are also aspects that require further consideration and optimisation in future. The trajectories of the particles could be made more reproducible by incorporating a flow focusing design for particle introduction, ensuring that all particles enter the chamber at the same position. The magnet could be placed next to the chamber, rather than on top of the chip, to ensure particles travel in the same horizontal plane instead of at different depths. These would help to eliminate discrepancies in particle intensity due to the "streaking" effect described earlier. Further improvements could include automation of the particle analysis, which is currently performed manually in ImageJ. However, while we currently employ a fluorescence microscope for image collection and analysis, we foresee the use of miniaturised fluorescence detection systems ${ }^{51,52}$ since we would not need to image a large area, instead requiring only that the magnetic particles pass through a small detection zone (such as that offered by laser-induced fluorescence detection). Furthermore, initial setup times for the platform, currently quite long at up to $45 \mathrm{~min}$ (including all steps such as binding primary antibodies to magnetic particles, preparation of chip and interfacing, washing of chip), could be significantly improved. This could be achieved by introducing an extra multilaminar flow reaction step to bind the primary antibodies to the magnetic particles on-chip rather than off-chip, while the set up with the syringes and syringe pump could also be improved.

However, these potential improvements represent a longer term vision for the system, while even in its current state it has proven capable of performing clinically relevant assays. We envisage the application of the system for the detection of a variety of biomarkers the patient's bedside, while requiring only a small volume of sample.

Table 2. Comparison of experimental parameters between conventional ELISA tests, off-chip magnetic particle assays, and the on-chip multilaminar flow assay for CRP determination.

\begin{tabular}{|l|c|c|c|}
\hline & ELISA & Off-chip & On-chip \\
\hline CRP binding step & $45 \mathrm{~min}$ & $15 \mathrm{~min}$ & $6-10 \mathrm{~s}$ \\
\hline Labelling step & $20 \mathrm{~min}$ & $15 \mathrm{~min}$ & $6-10 \mathrm{~s}$ \\
\hline Washing steps & $15 \mathrm{~min}$ & $20 \mathrm{~min}$ & $12-20 \mathrm{~s}$ \\
\hline Total time & $\mathbf{8 0 ~} \mathbf{~ m i n}$ & $\mathbf{5 0} \mathbf{~ m i n}$ & $<\mathbf{~ m i n}$ \\
\hline Volume of sample & $5 \mu \mathrm{L}$ & $200 \mu \mathrm{L}$ & $<10 \mu \mathrm{L}$ \\
\hline Volume of reagents & $300 \mu \mathrm{L}$ & $200 \mu \mathrm{L}$ & $<10 \mu \mathrm{L}$ \\
\hline Volume of wash soln. & $1.5 \mathrm{~mL}$ & $1.8 \mathrm{~mL}$ & $<30 \mu \mathrm{L}$ \\
\hline Volume of waste & $\mathbf{1 . 9} \mathbf{~ m L}$ & $\mathbf{2 . 2} \mathbf{~ m L}$ & $<\mathbf{5 0} \boldsymbol{\mu L}$ \\
\hline
\end{tabular}

\section{CONCLUSIONS}

We have demonstrated the application of a multilaminar flow platform, in which functionalised magnetic particles are pulled through alternating streams of reagents and washing buffers, for the quantitative detection of the inflammatory biomarker C-reactive protein from human serum samples. The two-step sandwich immunoassay required only 60 seconds, the time taken for the particles to cross the chamber through each of the streams. This is a vast improvement on conventional magnetic particle-based assay procedures, and removes the laborious manual operations usually required in such techniques. The detection of a clinically relevant biomarker opens the door for its application to the detection of a wider range of important biomolecules in rapid timeframes and with minimal sample and reagent usage.

\section{ASSOCIATED CONTENT}

\section{Supporting Information}

Supporting Information Available: A more detailed experimental section and parameters used for the simulations, in addition to data described but not shown in the manuscript. This material is available free of charge via the Internet at http://pubs.acs.org.

\section{AUTHOR INFORMATION}

\section{Corresponding Author}

* Tel: +44 (0) 1482 465027; Fax: +44 (0) 1482 466410; E-mail: n.pamme@hull.ac.uk.

\section{Present Addresses}

$\uparrow$ School of Physics and Astronomy, University of Leeds, Woodhouse Lane, Leeds, LS2 9JT, UK.

\section{Author Contributions}

All authors have given approval to the final version of the manuscript.

\section{ACKNOWLEDGMENT}

C.P.thanks the Royal Thai Government, Thailand, for financial support, while M.D.T. and S.A.P. thank the Engineering and Physical Sciences Research Council (EPSRC), UK. The authors acknowledge Dr Steve Clark for fabrication of the microfluidic devices, and Richard Alexander for assistance in developing the COMSOL model.

\section{REFERENCES}

(1) Clyne, B.; Olshaker, J. S. J. Emerg. Med. 1999, 17, 10191025.

(2) Black, S.; Kushner, I.; Samols, D. J. Biol. Chem. 2004, 279, 48487-48490.

(3) Lagrand, W. K.; Visser, C. A.; Hermens, W. T.; Niessen, H. W. M.; Verheugt, F. W. A.; Wolbink, G. J.; Hack, C. E. Circulation 1999, 100, 96-102.

(4) In American Heart Association website; American Heart Association.

(5) Casas, J. P.; Shah, T.; Hingorani, A. D.; Danesh, J.; Pepys, M. B. J. Intern. Med. 2008, 264, 295-314.

(6) Greenland, P.; Alpert, J. S.; Beller, G. A.; Benjamin, E. J.; Budoff, M. J.; Fayad, Z. A.; Foster, E.; Hlatky, M. A.; Hodgson, J. M.; Kushner, F. G.; Lauer, M. S.; Shaw, L. J.; Smith, J. S. C.; Taylor, A. J.; Weintraub, W. S.; Wenger, N. K. J. Am. Coll. Cardiol. 2010, 56, 21822199.

(7) In Medline Plus website; Medline Plus.

(8) Bhattacharyya, A.; Klapperich, C. M. Biomed. Microdev. 2007, 9, 245-251.

(9) Yang, Y. N.; Lin, H. I.; Wang, J. H.; Shiesh, S. C.; Lee, G. B. Biosens. Bioelectron. 2009, 24, 3091-3096. 
(10) Pankhurst, Q. A.; Connolly, J.; Jones, S. K.; Dobson, J. J. Phys. D: Appl. Phys. 2003, 36, R167-R181.

(11) Rios, A.; Zougagh, M.; Bouri, M. Anal. Methods 2013, 5, 4558-4573.

(12) Kriz, K.; Ibraimi, F.; Lu, M.; Hansson, L. O.; Kriz, D. Anal. Chem. 2005, 77, 5920-5924.

(13) Zhu, X. S.; Duan, D. Y.; Publicover, N. G. Analyst 2010, 135, 381-389.

(14) Meyer, M. H. F.; Hartmann, M.; Krause, H. J.; Blankenstein, G.; Mueller-Chorus, B.; Oster, J.; Miethe, P.; Keusgen, M. Biosens. Bioelectron. 2007, 22, 973979.

(15) Ibraimi, F.; Kriz, D.; Lu, M.; Hansson, L. O.; Kriz, K. Anal. Bioanal. Chem. 2006, 384, 651-657.

(16) Tarn, M. D.; Pamme, N. In Elsevier Reference Module in Chemistry, Molecular Sciences and Chemical Engineering, Reedijk, J., Ed.; Elsevier: Waltham, MA, 2013.

(17) Ng, A. H. C.; Uddayasankar, U.; Wheeler, A. R. Anal. Bioanal. Chem. 2010, 397, 991-1007.

(18) Tarn, M. D.; Pamme, N. Expert Rev. Mol. Diagn. 2011, 11,711-720.

(19) Mohammed, M.-I.; Desmulliez, M. P. Y. Lab Chip 2011, 11, 569-595.

(20) Pultar, J.; Sauer, U.; Domnanich, P.; Preininger, C. Biosens. Bioelectron. 2009, 24, 1456-1461.

(21) Hosokawa, K.; Omata, M.; Sato, K.; Maeda, M. Lab Chip 2006, 6, 236-241.

(22) Hosokawa, K.; Omata, M.; Maeda, M. Anal. Chem. 2007, 79, 6000-6004.

(23) Gervais, L.; Delamarche, E. Lab Chip 2009, 9, 33303337.

(24) Baldini, F.; Carloni, A.; Giannetti, A.; Porro, G.; Trono, C. Sens. Actuators B Chem 2009, 139, 64-68.

(25) Christodoulides, N.; Mohanty, S.; Miller, C. S.; Langub, M. C.; Floriano, P. N.; Dharshan, P.; Ali, M. F.; Bernard, B.; Romanovicz, D.; Anslyn, E.; Fox, P. C.; McDevitt, J. T. Lab Chip 2005, 5, 261-269.

(26) Lee, G.; Park, I.; Kwon, K.; Kwon, T.; Seo, J.; Chang, W. J.; Nam, H.; Cha, G. S.; Choi, M. H.; Yoon, D. S.; Lee, S. W. Biomed. Microdev. 2012, 14, 375-384.

(27) Kim, C.-H.; Ahn, J.-H.; Kim, J.-Y.; Choi, J.-M.; Lim, K.C.; Jung Park, T.; Su Heo, N.; Gu Lee, H.; Kim, J.-W.; Choi, Y.-K. Biosens. Bioelectron. 2013, 41, 322-327.

(28) Kim, A. R.; Kim, J. Y.; Choi, K.; Chung, D. S. Talanta 2013, 109, 20-25.

(29) Pamme, N. Lab Chip 2006, 6, 24-38.

(30) Gijs, M. A. M.; Lacharme, F.; Lehmann, U. Chem. Rev. 2010, 110, 1518-1563.

(31) Pamme, N. Curr. Opin. Chem. Biol. 2012, 16, 436-443.
(32) Tekin, H. C.; Gijs, M. A. M. Lab Chip 2013, 13, 47114739.

(33) Tarn, M. D.; Lopez-Martinez, M. J.; Pamme, N. Anal. Bioanal. Chem. 2014, 406, 139-161.

(34) Peyman, S. A.; Iles, A.; Pamme, N. Chem. Commun. 2008, 1220-1222.

(35) Peyman, S. A.; Iles, A.; Pamme, N. Lab Chip 2009, 9, 3110-3117.

(36) Peyman, S. A.; Patel, H.; Belli, N.; Iles, A.; Pamme, N. Magnetohydrodynamics 2009, 45, 361-370.

(37) Vojtíšek, M.; Iles, A.; Pamme, N. Biosens. Bioelectron. 2010, 25, 2172-2176.

(38) Tarn, M. D.; Fakhrullin, R. F.; Paunov, V. N.; Pamme, N. Mater. Lett. 2013, 95, 182-185.

(39) Sasso, L. A.; Undar, A.; Zahn, J. D. Microfluid. Nanofluid. 2010, 9, 253-265.

(40) Sasso, L. A.; Aran, K.; Guan, Y.; Ündar, A.; Zahn, J. D. Artif. Organs. 2013, 37, E9-E17.

(41) Ibraimi, F.; Kriz, D.; Lu, M.; Hansson, L. O.; Kriz, K. Analytical and Bioanalytical Chemistry 2006, 384, 651657.

(42) Gao, Y.; Lam, A. W. Y.; Chan, W. C. W. ACS Appl. Mater. Interfaces 2013, 5, 2853-2860.

(43) Ganguly, R.; Hahn, T.; Hardt, S. Microfluid. Nanofluid. 2010, 8, 739-753.

(44) Baier, T.; Mohanty, S.; Drese, K. S.; Rampf, F.; Kim, J.; Schoenfeld, F. Microfluid. Nanofluid. 2009, 7, 205-216.

(45) Karle, M.; Miwa, J.; Czilwik, G.; Auwaerter, V.; Roth, G.; Zengerle, R.; von Stetten, F. Lab Chip 2010, 10, 3284-3290.

(46) Karle, M.; Woehrle, J.; Miwa, J.; Paust, N.; Roth, G.; Zengerle, R.; von Stetten, F. Microfluid. Nanofluid. 2011, 10, 935-939.

(47) Tsai, S. S. H.; Wexler, J. S.; Wan, J.; Stone, H. A. Appl. Phys. Lett. 2011, 99, 153509.

(48) Tsai, S. S. H.; Wexler, J. S.; Wan, J.; Stone, H. A. Lab Chip 2013, 13, 119-125.

(49) McCreedy, T. TrAC, Trends Anal. Chem. 2000, 19, 396401.

(50) Snyder, L. R.; Kirkland, J. J.; Dolan, J. W. Introduction to Modern Liquid Chromatography, 3rd ed.; Wiley-VCH: New Jersey, 2010.

(51) Novak, L.; Neuzil, P.; Pipper, J.; Zhang, Y.; Lee, S. Lab Chip 2007, 7, 27-29.

(52) Zhu, H.; Isikman, S. O.; Mudanyali, O.; Greenbaum, A.; Ozcan, A. Lab Chip 2013, 13, 51-67. 